\title{
THE THICKNESS FUNCTIONS OF THE SHELLS OF REVOLUTION SUBJECTED TO AXISYMMETRICAL LOADS
}

\author{
Ngo Huong Nhu ${ }^{1}$, Pham Hong NGa ${ }^{2}$ \\ ${ }^{1}$ Institute of Mechanics \\ 2 University of Transport and Communication
}

\begin{abstract}
The inverse problems for determining the meridian shape or varying thickness function of momentless shells of revolution under given loads were concerned in many works $[2,3,4]$. However, for the complexity of loads or configuration of a shell these problems haven' $t$ been solved perfectly because of its mathematical difficulties.

In this paper, the problem for determining the thickness function of shells of revolution such as a parabola, sphere arc, under axisymmetrical loads is considered. The general integro-differential equations for determination of the meridian form and shell thickness are obtained. A solution of differential equations by semi-analytical and numerical methods for the thickness is presented. The numerical solutions are given for the parabola under external pressure, the sphere immerged in the fluid and the sphere arc. Obtained results may be used in the thin shell design.
\end{abstract}

\section{THE MOMENTLESS THEORY OF SHELLS OF REVOLUTION SUBJECTED TO AXISYMETRICAL LOADS}

The equilibrium equations are of the form [1]:

$$
\left\{\begin{array}{l}
\frac{d T_{s}}{d s}+\left(T_{\varepsilon}-T_{s}\right) \frac{\sin \theta}{r}+X=0 \\
\frac{T_{s}}{R_{1}}+\frac{T_{\varphi}}{R_{2}}=Z
\end{array}\right.
$$

where $T_{s}$ and $T_{\varphi}$ are membrane forces, $R_{1}, R_{2}$ are curvature radii of the shell, $\theta$ is the angle between the tangential line of the meridian and the $O z$ axis, $X, Z$ - the external load components, $r$ - radius of the hoop circle.

For the shell of revolution we have following useful relations [1]:

$$
\begin{aligned}
& \frac{1}{R_{1}}=\frac{d \theta}{d s} ; \quad \frac{1}{R_{2}}=\frac{\cos \theta}{r} ; \frac{d r}{d s}=-\sin \theta \\
& \frac{d}{d s}\left(\frac{1}{R_{2}}\right)=\left(\frac{1}{R_{2}}-\frac{1}{R_{1}}\right) \frac{\sin \theta}{r}
\end{aligned}
$$


Then, the relations between small deformations and displacements are:

$$
\left\{\begin{array}{l}
\varepsilon_{s}=\frac{d u}{d s}+\frac{w}{R_{1}}, \\
\varepsilon_{\varphi}=\frac{-\sin \theta}{r} u+\frac{w}{R_{2}} .
\end{array}\right.
$$

Corresponding to Hook theory, the strains $\varepsilon_{s}$ in the direction of a meridian and $\varepsilon_{\varphi}$ is perpendicular to a meridian are related to the membrane forces by equations:

$$
\left\{\begin{array}{l}
\varepsilon_{s}=\frac{1}{E h}\left(T_{s}-\nu T_{\varphi}\right), \\
\varepsilon_{\varphi}=\frac{1}{E h}\left(T_{\varphi}-\nu T_{s}\right)
\end{array}\right.
$$

where $E$ is the Young's moduls, $\nu$ is the Poisson's ratio and $h$ is the thickness of the shell.

\section{THE DIFFERENTIAL EQUATION FOR DETERMINATION OF THICKNESS FUNCTION}

From the condition of zero bending stresses, i. e. the curvature change is equal to zero, we have:

$$
\begin{aligned}
& \chi_{s}=-\frac{d}{d s}\left(\frac{d w}{d s}-\frac{u}{R_{1}}\right)=0, \\
& \chi_{\varphi}=-\frac{\sin \theta}{r}\left(\frac{d w}{d s}-\frac{u}{R_{1}}\right)=0,
\end{aligned}
$$

hence $\frac{d w}{d s}-\frac{u}{R_{1}}=0$.

Substituting this relation into the compatibility deformation equation and using (1.2):

$$
r \frac{d \varepsilon_{\varphi}}{d s}-\left(\varepsilon_{\varphi}-\varepsilon_{s}\right) \sin \theta-\left(\frac{d w}{d s}-\frac{u}{R_{1}}\right) \cos \theta=0 .
$$

We receive the condition of zero bending stresses in the form:

$$
r \frac{d \varepsilon_{\varphi}}{d s}-\left(\varepsilon_{\varphi}-\varepsilon_{s}\right) \frac{d r}{d s}=0 \quad \text { or } \quad \frac{d\left(r \varepsilon_{\varphi}\right)}{d r}=\varepsilon_{s} .
$$

The condition without bending stresses in the shell, is represented by the deformations. It is the basic relation to establish differential and integro-differential equations for determination of the shell thickness and meridian form.

The general solutions of the equilibrium system (1.1) have a form [1]:

$$
\begin{aligned}
& T_{s}=\frac{1}{r}\left[C+\int_{r_{0}}^{r}\left(Z+\frac{X}{\sqrt{\eta^{2}-1}}\right) r d r\right] \eta, \\
& T_{s}=Z r \eta+\left[C+\int_{r_{0}}^{r}\left(Z+\frac{X}{\sqrt{\eta^{2}-1}}\right) r d r\right] \frac{d \eta}{d r},
\end{aligned}
$$


where: $\eta=1 / \cos \theta=\sec \theta$.

Constant $C$ may be found from the following conditions:

At the boundary $r=r_{0}, T_{s}=T_{s}^{0}$, so that

$$
C=T_{s}^{0} r_{0} \cos \theta_{0}
$$

At the other boundary $r=r_{1}$, if $Q$ is resultant of vertical load components with intensity $p_{z}$, which are parallel to axis of revolution, then the condition will be:

$$
\begin{aligned}
& 2 \pi C=2 \pi T_{s}^{0} r_{0} \cos \theta_{0}=-Q \\
& Q=2 \pi r_{1} p_{z}, \quad C=-r_{1} p_{z} .
\end{aligned}
$$

The differential equation for thickness shell will be given by substituting (2.4) into (2.5)

$$
\begin{aligned}
& \frac{1}{h E}\left(T_{s}-v T_{\varphi}\right)=\frac{d}{d r}\left[\frac{r}{h E}\left(T_{\varphi}-\nu T_{s}\right)\right] \\
& \text { or } \quad \frac{1}{h} \frac{d h}{d r}=\frac{1}{r}+\frac{1}{T_{\varphi}-\nu T_{s}} \frac{1}{d r}\left(T_{\varphi}-\nu T_{s}\right)-\frac{T_{s}-\nu T_{\varphi}}{r\left(T_{\varphi}-\nu T_{s}\right)}
\end{aligned}
$$

The solution of which has the form:

$$
h(r)=h_{0} \frac{r}{r^{0}}\left|\frac{T_{\varphi}-\nu T_{s}}{T_{\varphi}^{0}-\nu T_{s}^{0}}\right| \exp \left[-\int_{r_{0}}^{r} \frac{T_{s}-\nu T_{\varphi}}{r\left(T_{\varphi}-\nu T_{s}\right)}\right] .
$$

where inner forces $T_{s}$ and $T_{\varphi}$ are determined from (2.2).

Substituting (2.2) into (1.4) and (2.1), we obtain the integro-differential equation for determining the shape of shells:

$$
\begin{aligned}
& r^{2} I \frac{d^{2} \eta}{d r^{2}}+r\left[I\left(1-\frac{r d h}{h d r}\right)+\left(2 r^{2} Z+\frac{r^{2} X}{\sqrt{\eta^{2}-1}}\right)\right] \frac{d \eta}{d r}+ \\
& +\eta\left[2 r^{2} Z-r^{3} Z \frac{d h}{h d r}+I\left(\frac{r v}{h} \frac{d h}{d r}-1\right)-\frac{r^{2} \nu Z}{\sqrt{\eta^{2}-1}}+r^{3} \frac{d X}{d r}\right]=0
\end{aligned}
$$

where: $I=\int_{r_{0}}^{r} r\left(Z+\frac{X}{\sqrt{\eta^{2}-1}}\right) d r+C$

Note that if the meridian form $\eta$ and external load components $X, Z$ are known, the equation (2.3) also can be given directly from this general integro-differential equation. The inner forces (2.3) in fact depend on the shell meridian form $\eta$ and external load components $X, Z$. They can be expressed in the clearly analytical form only for cases in which the integral can be analytically realized. We consider thickness solutions (2.4) for some different external loads and shells of revolution. 


\section{DETERMINATION THE THICKNESS $h=h(r)$ FOR THE SPHERE SHELL SUBJECTED TO DIFFERENT LOADS}

a. Consider a sphere shell of radius $R$, immerged in fluid with the mass density $\gamma$ and $a$ is the height of the fluid to the sphere boundary top (Fig. 1), then the external forces are [5]:

$$
\begin{aligned}
& p_{z}=\gamma(a+R-R \sin \theta), \\
& X=-\gamma(a+R-R \sin \theta) \sin \theta, \\
& Z=-\gamma(a+R-R \sin \theta) \sin \theta .
\end{aligned}
$$

where $\alpha+\theta=\pi / 2$.

For the sphere we have:

$$
\eta=R / r, \quad \sin \theta=\sqrt{R^{2}-r^{2}} / R, \quad \eta / d r=-R / r^{2} .
$$

Substituting these values into (2.2) and integrating it, we have the stress resultants:

$$
\begin{aligned}
& T_{s}(r)=\frac{R}{r^{2}}\left\{\gamma R\left[(a+R) \sqrt{R^{2}-r^{2}}+\frac{r^{2}-R^{2}}{2}+C\right]\right\}, \\
& T_{\varphi}(r)=\gamma\left[a+R-\sqrt{R^{2}-r^{2}}\right] \sqrt{R^{2}-r^{2}}-T_{s}(r) .
\end{aligned}
$$

Note that, the force $T_{s}$ acting in the boundary $r_{0}=R$ is:

$$
T_{s}^{0}=T_{s}(R)=\frac{C}{R}
$$

In other hand, constant $C$ may be found from $(2.2 \mathrm{~b})$ :

$$
C=-r_{1} p_{z}
$$

where $p_{z}$ is the force intensity at the $r=r_{1}$ :

$$
\begin{aligned}
& p_{z}=\gamma\left(a+R-R \cos \alpha_{1}\right), \\
& \cos \alpha_{1}=\sqrt{1-\left(\frac{r_{1}}{R}\right)^{2}} .
\end{aligned}
$$

Consequently constant $C$ and $T_{s}^{0}$ will be defined.

The function $h(r)$ can be given by substituting (3.1), (3.2) into (2.4) and integrating this expression by Simpson's method. The values of function $h(r)$ are obtained in discrete numerical form.

The numerical example is realized with the following geometric and load parameters: $r_{0}=R=1.3 \mathrm{~m} ; h_{0}=0.01 \mathrm{~m} ; \gamma=9810 \mathrm{~N} / \mathrm{m}^{3} ; a=1 \mathrm{~m} ; r_{1}=r\left(\alpha_{1}\right)=0.5 \mathrm{~m} ; \nu=$ $0.33 ; C=-5395.5 \mathrm{~N}, T_{s}^{0}=-4150.38 \mathrm{~N} / \mathrm{m}, T_{\varphi}^{0}=4150.38 \mathrm{~N} / \mathrm{m}$. The discrete results and graphical form are presented in the Fig. 1.

Note that, in this case, when the shell is immerged in the fluid, the thickness values decrease from the top of the shell to its bottom. 


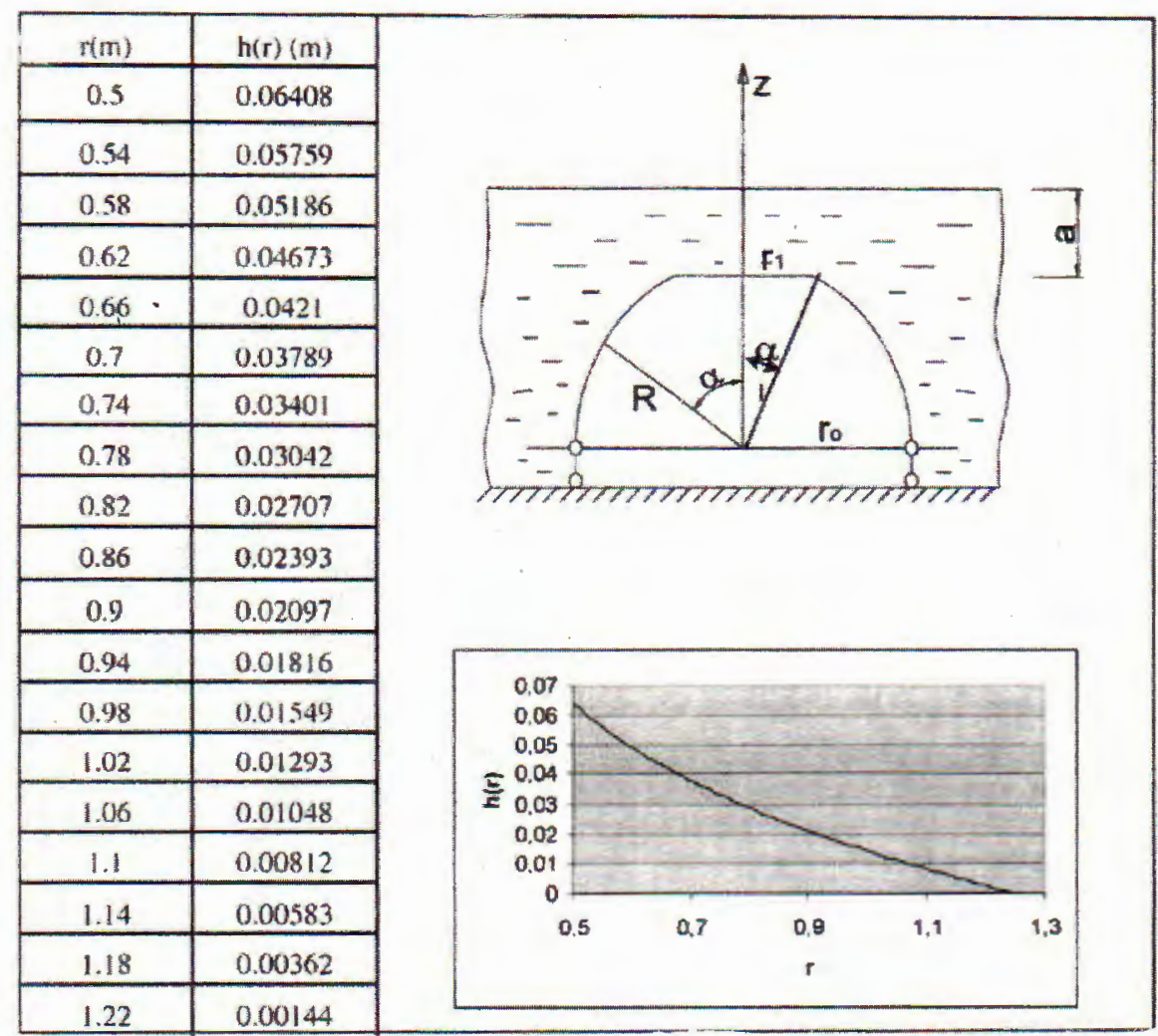

Fig. 1. The thickness $h(r)$ for sphere shell immerged in the fluid

b. Consider the shell of revolution obtained from a sphere arc subjected to the uniformly external pressure $p$ (Fig. 2).

In this case, the geometrical characteristics are [1]:

$$
\begin{aligned}
& R_{1}=R ; \quad R_{2}=\frac{r}{\cos \theta}=\frac{R \cos \theta-a}{\cos \theta}, \\
& \Rightarrow \eta=\frac{1}{\cos \theta}=\frac{R}{r+a} ; \quad \frac{d \eta}{d r}=-\frac{R}{(r+a)^{2}} .
\end{aligned}
$$

The external load components have the form:

$$
Z=p=\text { const }, \quad X=0, \quad C=T_{s}^{0} \frac{r_{0}\left(r_{0}+a\right)}{R} .
$$

Then the stress resultants in the shell according to (2.2) will be:

$$
\begin{aligned}
& T_{s}=\frac{R p}{2 r(r+a)}\left(r^{2}-r_{0}^{2}\right)+T_{s}^{0} \frac{r_{0}\left(r_{0}+a\right)}{R}, \\
& T_{\varphi}=\frac{r}{r+a}\left[p R-T_{s}\right] .
\end{aligned}
$$

Substituting these forces into expressions (2.4) we can determine the function $h(r)$ Numerical example is illustrated for this type shell with the following geometrical and 
loading parameters:

$$
\begin{aligned}
& r_{0}=0.5 m \quad r_{1}=1.6 m, \quad h_{0}=0.02 m \quad R=3.1 m, \quad a=1.5 m \\
& \nu=0.33, \quad p=-2100000 N / m^{2}, \quad r \in[0.5 m ; 1.6 m], \quad T_{s}^{0}=0(\mathrm{~N} / \mathrm{m}) .
\end{aligned}
$$

The results in the Fig. 2 show that the thickness at the boundary $R$ needs approximately three times larger than the initial thickness at the $r=r_{0}$.

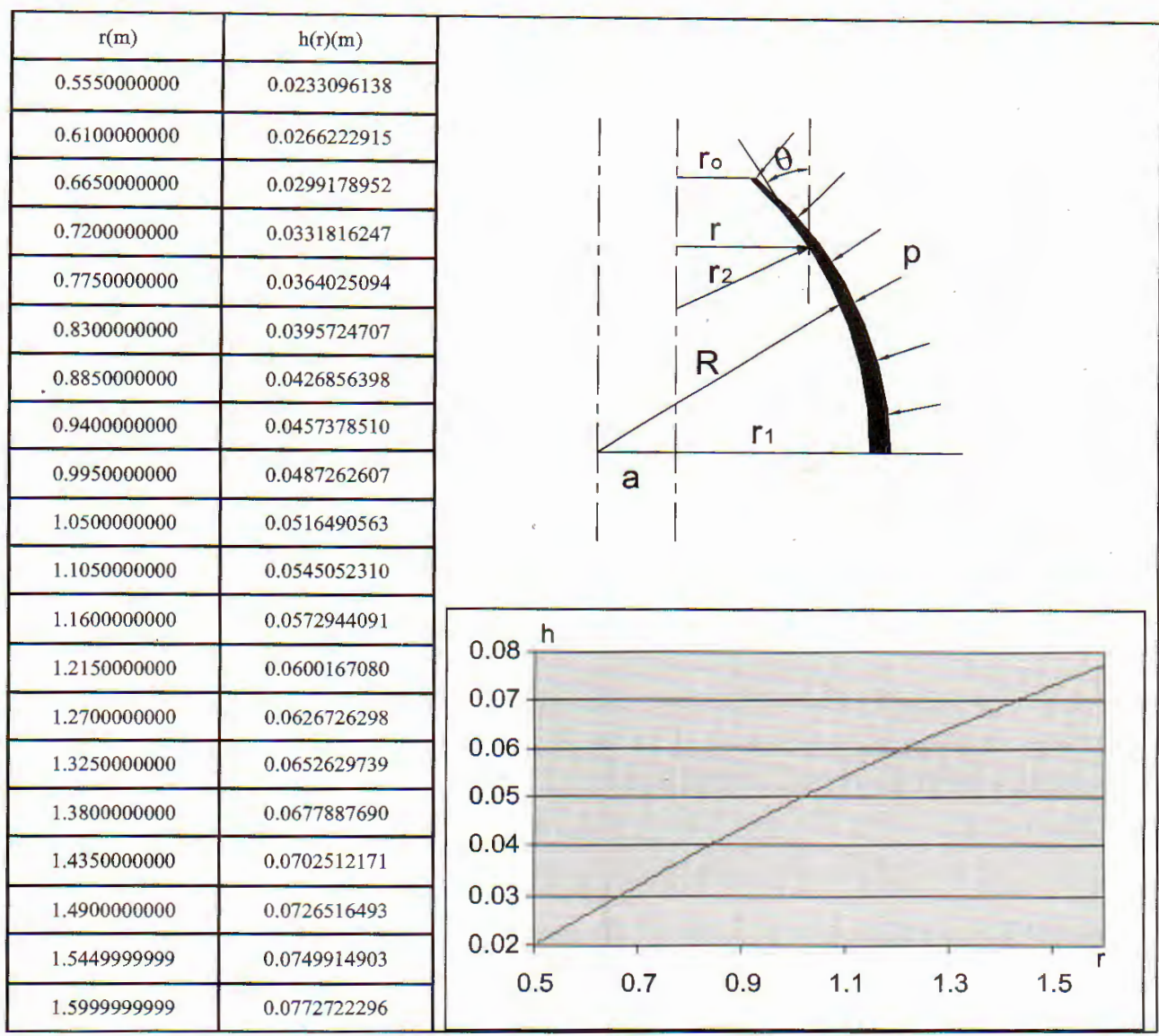

Fig. 2. The thickness $h(r)$ for the shell subjected to uniform load

\section{DETERMINATION OF THE THICKNESS $h=h(r)$ FOR THE SHELL OF REVOLUTION OBTAINED FROM OF PARABOLA ARC, SUBJECTED TO THE UNIFORMLY EXTERNAL PRESSURE $p$}

We consider the parabola shell, its meridian equation is (Fig. 3) [5]:

$$
p^{2}=2 a\left(h_{1}-z\right)
$$

$a$ is parameter of the parabola, $h_{1}$ is the height of parabola arc. 


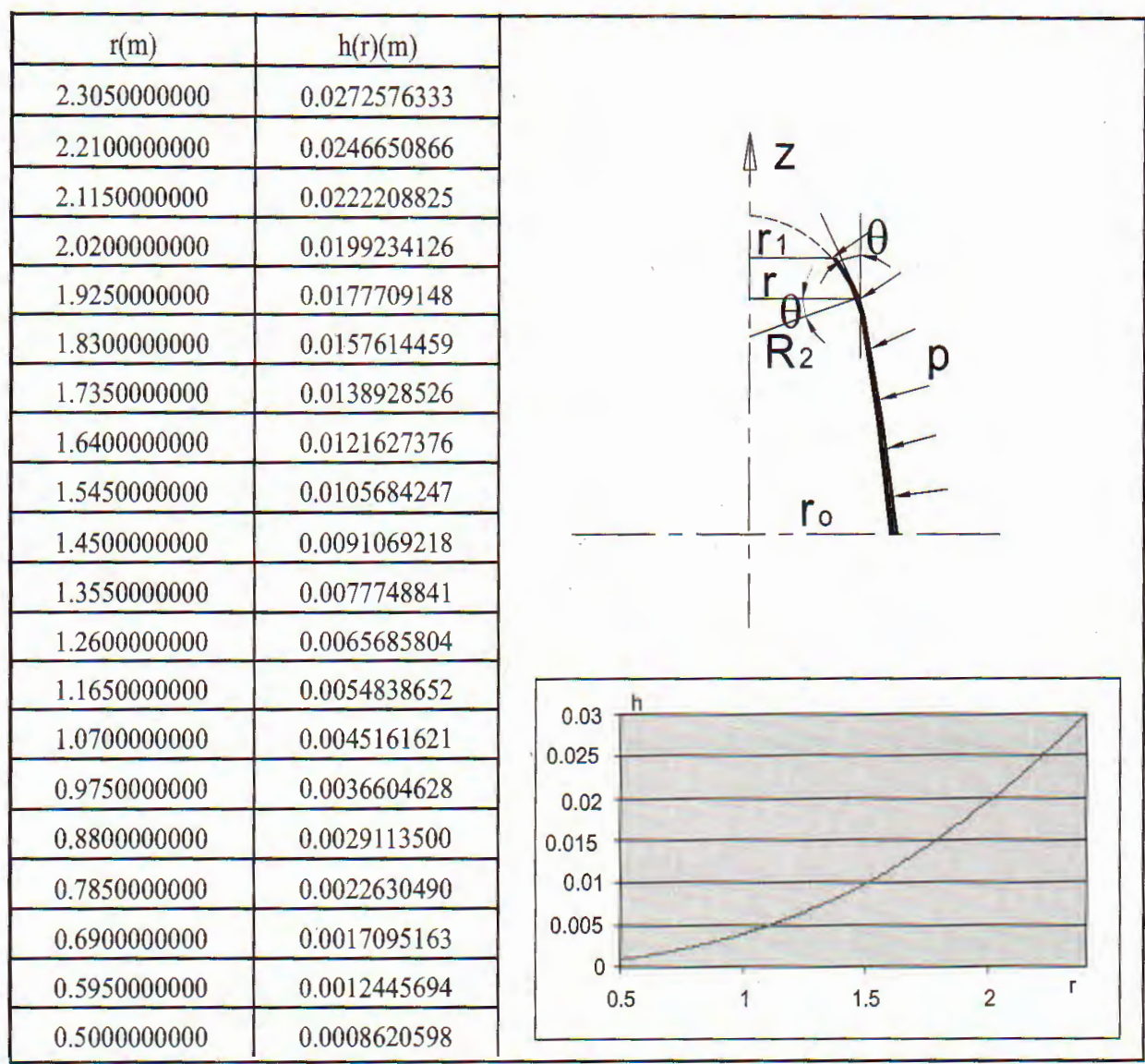

Fig. 3. The thickness $h(r)$ for the shell of revolution

Note that if $z$ denotes the distance along the axis of revolution, then a relationship between $r$ and $z$ has a form:

$$
\frac{d r}{d z}= \pm \sqrt{\eta^{2}-1}
$$

from (4.1) and (4.2) we have

$$
\eta=\sqrt{1+\frac{a^{2}}{r^{2}}}, \quad \frac{d \eta}{d r}=-\frac{a^{2}}{r^{3}}\left(1+\frac{a^{2}}{r^{2}}\right)^{-1 / 2} .
$$

In this case, the external load components have the form:

$$
Z=p=\text { const }, \quad X=0, \quad C=0 .
$$

Substitute (4.3) and (4.4) into (2.2), the stress resultants in the parabola shell will be:

$$
\begin{aligned}
& T_{s}=\frac{p}{2} \sqrt{a^{2}+p^{2}} \\
& T_{\varphi}=\frac{p a^{2}+2 r^{2}}{2 \sqrt{a^{2}+r^{2}}} .
\end{aligned}
$$

The function $h(r)$ can be calculated by numerically integrating the expression $(2.4)$. 
This example aims to define the function thickness $h(r)$ of the parabola shell with following geometrical and loading parameters: $r_{0}=2.4 m ; h_{0}=0.03 m ; a=2.1 m ; r_{1}=$ $0.5 m ; \nu=0.3 ; p=475000 \mathrm{~N} / \mathrm{m}^{2}, T_{s}^{0}=0(\mathrm{~N} / \mathrm{m})$.

The given discrete values of solution $h(r)$ are shown in the Fig. 3.

Note that, the thickness at the boundary $R=r_{0}$ is larger than the thickness at the $R=r_{1}\left(r_{1}<r_{0}\right)$.

The similar problems may be solved by obtained calculating programs.

\section{CONCLUSION}

In this paper, the differential equation for determining the thickness function of shells of revolution under axisymmetric loads is presented. This equation is solved by semianalytical and numerical methods. The thickness functions of many different shells of revolution as parabola shell, sphere shells immerged in fluid under different loads are given in the discrete value tables or in the graph forms. The solutions of these inverse problems may be used in structural design.

This work is completed with financial support of the Council for Natural Science of Vietnam.

\section{REFERENCES}

1. A.C. Ambarshumian, Theory of Anisotropic Shell, Moscow, 1966.

2. M. D. Martunhenco, Ngo Huong Nhu, Determine forms of thermoelastic shell of revolution, made of non-linear materials, Report. Scien Acad. BSSR 31 (1987) 619-622.

3. Ngo Huong Nhu. The forms of the shell with zero bending stresses subjected to hydrostatic pressure and other loads, Journal of Mechanics 19 (2) (1997) 39-43.

4. Ngo Huong Nhu, Pham Hong Nga, The varying thickness rules of the revolution shells subjected to combine external loads, Proceedings of the Seventh National Congress on Mechanics, Ha Noi, 3 (2002)403-409.

5. A. A. Umanskii, Designer Handbook, Calculate-Theoretical, V2. Construction Literature Publisher, Moscow, 1973.

Received October 24, 2003

Revised April 20, 2005

\section{HÀM Độ DÀY CƯA CÁC VỎ TRÒN XOAY DẠNG PARABOL VÀ VỎ CẦU CHỊU TÁC DỤNG CƯA TẢI ĐỐI XỨNG TRỤC}

Bài báo đã giải một lớp bài toán ngược xác định hàm độ dày của các vơ tròn xoay như vỏ parabol, vổ cầu chịu tải đối xứng trục. Phương trình vi tích phân chung xác đinh hình dạng đường sinh vơ và độ dày vỏ đã được đưa ra. Nghiệm của phương trình hàm dộ dày đã được tính bằng phương pháp nưa giải tích và số. Các thí dụ số đã được thực hiện cho vơ parabol chịu tải phân bố đều tác dụng vuông góc lên mặt vớ, vơ cầu ngâm trong chất lơng, vơ quay bằng một cung cầu quanh trục cách trục $z$ một khoảng $a$. Các hàm độ dày nhận được bằng các chương trình tính toán và kết quả cho dưói dạng bảng số các giá trị rời rạc hoặc đồ thị . Các kết quả có thể dùng tham khảo trong thiết kế vơ mơng. 